\title{
Aufteilung der Kommentierung
}

Baumesster, Wilhelm $\$$ 1372-1390 BGB

$\$ 53$ a FGG

Fehmel, Hans-Werner $\$ 1361$ a, b, 1634, 1671, 1672, 1696 BGB

\$S $1-27$ HausrVO

$\iint 50 \mathrm{a}-\mathrm{d}$ FGG

Griesche, Gerhard $\quad \int 1361,1569-1586 \mathrm{~b}, 1601-1615$ BGB

$\int \S 253,254,256,258,265,323,767,916,940 \mathrm{ZPO}$

Hochgräber, Gerhard

$\int 1629 \mathrm{BGB}$

If 93 a, 97, 114, 115, 117-121, 124, 127, 127 a, 708, 709 ZPO

$\int \$ 13 a, 20$ a FGG

$\int \S 1,12,14,17,17$ a, 18, 19 a 20, 65 GKG

$\int \S 1-3,5,7,8,18,30,94,97,99,131,131$ a KostO

Kayser, August

$\int 1564-1568 \mathrm{BGB}$

$\int 7_{8}, 606-630 \mathrm{ZPO}$

$\$ 64$ FGG

If 23 a -c, 72, 119, 133, 138, 170, 199, 200 GVG

Wick, Hartmut
1587-1587 p BGB
IS $1-13$ VAHRG
$\int \S 1-5$ VAÜG
$\int \$ 53 \mathrm{~b}-\mathrm{g}$ FGG 
